\title{
Palonosetron in the prevention of chemotherapy- induced nausea and vomiting: an evidence-based review of safety, efficacy, and place in therapy
}

This article was published in the following Dove Press journal:

Core Evidence

2I August 2015

Number of times this article has been viewed

\section{Luigi Celio}

Monica Niger

Francesca Ricchini

Francesco Agustoni

Medical Oncology Unit I, Department of Medical Oncology, Fondazione IRCCS Istituto Nazionale Tumori, Milan, Italy
Correspondence: Luigi Celio

Medical Oncology Unit I, Department of Medical Oncology, Fondazione IRCCS Istituto Nazionale Tumori, Via Venezian I, 20133 Milan, Italy

Tel +3902 23902597

Fax +39022390 3678

Email luigi.celio@istitutotumori.mi.it
Introduction: The second-generation 5-hydroxytryptamine-3 $\left(5-\mathrm{HT}_{3}\right)$ receptor antagonist palonosetron is effective in the prevention of chemotherapy-induced nausea and vomiting (CINV) associated with highly and moderately emetogenic chemotherapy (HEC and MEC, respectively). In addition, palonosetron has been the first and, at present, the only 5-HT 3 receptor antagonist to have a specific indication for the prevention of delayed CINV associated with MEC. The unique pharmacology of this antagonist is thought to partly explain its improved efficacy against delayed symptoms.

Aims: To review the evidence underlying the use of palonosetron in preventing CINV.

Evidence review: A recent meta-analysis consistently showed that palonosetron significantly increases the control of both emesis and nausea during the acute and delayed phases after single-day HEC or MEC. Consistent with these findings from trials that did not include an neurokinin-1 (NK-1) receptor antagonist, randomized controlled trials recently showed that a triple combination with palonosetron achieves significantly better control of delayed CINV, particularly delayed nausea, in patients undergoing HEC or the high-risk combination of an anthracycline and cyclophosphamide (AC). Evidence from randomized studies also supports palonosetron as a valuable option to reduce the total corticosteroid dose administered in patients undergoing multiple cycles of MEC or AC chemotherapy. Additional benefits of palonosetron include the lack of a warning on cardiac safety and no known clinically significant drug-drug interactions.

Place in therapy and conclusion: Evidence currently available indicates that palonosetron significantly adds to the clinician's ability to effectively control CINV in patients undergoing HEC or MEC. It is recommended in the international guidelines for the prevention of CINV caused by MEC. The high safety profile and the opportunity to reduce the total corticosteroid dose with no loss in efficacy against delayed CINV should also contribute to a wider use of palonosetron in clinical practice.

Keywords: palonosetron, 5- $\mathrm{HT}_{3}$ receptor antagonist, CINV, moderately emetogenic chemotherapy, highly emetogenic chemotherapy, dexamethasone

Core evidence place in therapy summary for palonosetron in the prevention of chemotherapy-induced nausea and vomiting

\begin{tabular}{lll}
\hline $\begin{array}{l}\text { Outcome } \\
\text { measure }\end{array}$ & Evidence & Implications \\
\hline $\begin{array}{l}\text { Patient-oriented evidence } \\
\text { Control of emesis Clear }\end{array}$ & $\begin{array}{l}\text { Use of palonosetron in combination with dexamethasone } \\
\text { with or without a neurokinin-I antagonist improves control of } \\
\end{array}$ \\
& $\begin{array}{l}\text { acute and delayed emesis in patients receiving moderately or } \\
\text { highly emetogenic chemotherapy }\end{array}$
\end{tabular}




\begin{tabular}{|lll|}
\hline $\begin{array}{l}\text { (Continued) } \\
\text { Outcome } \\
\text { measure }\end{array}$ & Evidence & Implications \\
\hline Control of nausea & Clear & $\begin{array}{l}\text { Use of palonosetron in combination with dexamethasone } \\
\text { with or without a neurokinin-I antagonist improves control of } \\
\text { acute and delayed nausea in patients receiving moderately or } \\
\text { highly emetogenic chemotherapy }\end{array}$ \\
$\begin{array}{lcll}\text { Patient satisfaction } \\
\text { Economic evidence } \\
\text { Cost effectiveness }\end{array}$ & Moderate & $\begin{array}{l}\text { Patients experience less impact of nausea and vomiting on daily } \\
\text { activities when palonosetron used }\end{array}$ \\
& $\begin{array}{l}\text { Acquisition costs of palonosetron may be partially offset by } \\
\text { savings made in other health care resources }\end{array}$ \\
\hline
\end{tabular}

\section{Scope, aims, and objectives}

Palonosetron (Aloxi ${ }^{\circledR}$, Helsinn Healthcare SA, Pazzallo, Switzerland) is a selective 5-hydroxytryptamine-3 (5- $\left.\mathrm{HT}_{3}\right)$ receptor antagonist, which was approved by the US Food and Drug Administration (FDA) for use with other antiemetics in the prevention of acute nausea and vomiting associated with initial and repeat courses of highly or moderately emetogenic chemotherapy (HEC and MEC, respectively) and in the prevention of delayed nausea and vomiting associated with initial and repeat courses of MEC in 2003. In 2005, the European Medicines Agency (EMA) approved the product with indications similar to those in the US.

This article reviews the evidence for the place of palonosetron in the prevention of the acute and delayed chemotherapy-induced nausea and vomiting (CINV).

\section{Methods}

The article builds on a recent systematic review with metaanalysis of randomized controlled trials (RCTs) that evaluated the efficacy and safety of palonosetron in relation to other $5-\mathrm{HT}_{3}$ receptor antagonists for the prevention of CINV in the clinical setting up to June 2013. ${ }^{1}$ Therefore, the methodology employed here provides an update to this analysis to include RCTs of palonosetron in combination with a neurokinin-1 (NK-1) receptor antagonist as well as RCTs of a dexamethasone-sparing approach with palonosetron. The MEDLINE database was searched via PubMed, as well as conference proceedings from the American Society of Clinical Oncology and European Society for Medical Oncology (ESMO). An English language literature search was conducted between January 1, 2003 and May 31, 2015 using the search term "palonosetron" and limits "randomized controlled trial, meta-analysis, and clinical trial". The published articles and conference abstracts identified were screened for the selection of relevant studies. Adequately powered RCTs were included if they assessed at least one of the following common efficacy end points (primary and secondary): 1) the percentage of patients achieving complete response (CR);2) the percentage of patients achieving no emetic episodes; and 3) the percentage of patients achieving no episodes of nausea. All the end points were examined within the acute, delayed, and overall (days 1-5 postchemotherapy) phases. Studies were excluded if they contained repeat data. Although the meta-analysis included a total of 16 RCTs of palonosetron in the prevention of CINV, we identified eight additional full papers and two meeting abstracts after screening for eligibility. ${ }^{2-11}$ In addition, this paper reviews the available evidence supporting the introduction of an oral palonosetron formulation as well as investigates the recent FDA approval of palonosetron for use in the pediatric setting.

\section{Introduction to palonosetron}

Nausea and vomiting remain common distressing side effects in patients receiving HEC and MEC. CINV has been traditionally categorized as acute or delayed: acute CINV occurs within 24 hours after initiation of chemotherapy (acute phase), whereas delayed emesis occurs between days 2 and 5 (delayed phase). ${ }^{12}$ Increased risk of CINV depends not only on the emetogenicity of the chemotherapeutic agent administered but also on patient-related characteristics such as younger age, female sex, and a history that includes no alcohol consumption, morning sickness, and prior emetic episodes after chemotherapy. ${ }^{12}$

The mechanism of delayed emesis has been most extensively investigated in patients receiving highly emetogenic cisplatin, but it also occurs with moderately emetogenic agents, including cyclophosphamide, anthracyclines, and carboplatin. ${ }^{13}$ The most striking finding of a survey in clinical oncology practices was that the vast majority of experienced physicians and nurses underestimated the extent to which delayed CINV occurs after both HEC and MEC. ${ }^{14}$ Delayed CINV occurs more frequently than acute CINV, with reported incidence rates of $28 \%-50 \%$ for delayed emesis and $52 \%-60 \%$ for delayed nausea. ${ }^{14}$ However, the rates of 
delayed emesis can also differ among the reported studies due to factors that are known to increase the risk of this adverse event. ${ }^{13}$ The most significant among the predictive factors is the failure to obtain complete protection against acute emesis. In patients receiving cisplatin who were followed up throughout repeat chemotherapy cycles, not only the incidence of delayed vomiting in the second/third cycles depended on the protection against emesis achieved in the acute phase of the same cycles, but also the occurrence of delayed vomiting was a predictor of acute emesis in the subsequent cycles of chemotherapy. ${ }^{15}$ A large, randomized study demonstrated that the efficacy of prophylaxis against delayed CINV caused by MEC is also strongly influenced by the occurrence of acute symptoms. ${ }^{16}$

The use of first-generation $5-\mathrm{HT}_{3}$ receptor antagonists, including ondansetron, granisetron, and dolasetron, represented a major advance in the management of acute CINV. ${ }^{12}$ However, these agents, when used in the recommended doses, do not add significant efficacy to that obtained by dexamethasone alone in the control of delayed emesis. ${ }^{16-18}$ The newest agent in the setron class, palonosetron, has been the first and, at present, the only $5-\mathrm{HT}_{3}$ receptor antagonist to have a specific indication for the prevention of delayed CINV. The unique pharmacology of this second-generation $5-\mathrm{HT}_{3}$ receptor antagonist is thought to partly explain its improved efficacy against delayed CINV. ${ }^{19,20}$

\section{Pharmacology of palonosetron}

Palonosetron hydrochloride is an isoquinolone hydrochloride with a molecular weight of $332.87 \mathrm{Da}$. It exists as a single isomer, and is freely soluble in water. Palonosetron is believed to prevent emesis by blocking the binding of serotonin to $5-\mathrm{HT}_{3}$ receptors located on the nerve terminals of the vagus in the gastrointestinal tract and centrally in the chemoreceptor trigger zone of the area postrema. Palonosetron has not only greater $5-\mathrm{HT}_{3}$ receptor binding affinity (at least 30-fold higher) and longer plasma elimination half-life (approximately 40 hours) compared with older antagonists, but also has a unique interaction with the $5-\mathrm{HT}_{3}$ receptor at the molecular level. ${ }^{21}$ There is evidence that palonosetron exhibits allosteric interactions and positive cooperativity with the $5-\mathrm{HT}_{3}$ receptor and that these characteristics are not displayed by ondansetron and granisetron. ${ }^{21}$ The binding of palonosetron elicits receptor internalization, which results in a prolonged inhibition of serotonin signaling. ${ }^{22}$ Finally, palonosetron inhibits cross-talk between $5-\mathrm{HT}_{3}$ and NK-1 signaling pathways. ${ }^{23}$ Overall, these properties of palonosetron could offer advantages of both efficacy and convenience over older antagonists as the drug may continue to maintain effective $5-\mathrm{HT}_{3}$ receptor blockade even when it is no longer detectable in plasma.

Mean maximum plasma concentrations and area-underthe-concentration-time curve generally increased in a dosedependent manner over the dose range of $0.3-90 \mu \mathrm{g} / \mathrm{kg}$ palonosetron in healthy subjects and in cancer patients. ${ }^{24,25}$ Palonosetron has a low total clearance and elevated levels of volume of distribution. The drug is eliminated from the body through renal excretion and metabolic pathways that are mediated via multiple CYP enzymes, including CYP2D6, and to a lesser extent, CYP3A and CYP1A2. The potential for clinically significant drug interactions with palonosetron appears to be low, and dosage adjustment is not necessary for patients with renal or hepatic impairment. ${ }^{24,25}$ Palonosetron is available as an intravenous injection (single dose of $0.25 \mathrm{mg}$ in Western countries; single dose of $0.75 \mathrm{mg}$ in Japan) and orally.

\section{Safety profile of palonosetron Common adverse events}

The unique pharmacology of palonosetron may theoretically lead to different side effects. With respect to safety, the meta-analysis reported on all of the most common $5-\mathrm{HT}_{3}$ receptor antagonist-related adverse events such as constipation, headache, diarrhea, and dizziness. ${ }^{1}$ The results of safety end points comparing palonosetron to other $5-\mathrm{HT}_{3}$ receptor antagonists in the prevention of CINV are summarized in Table 1. The meta-analysis showed statistical similarity between palonosetron and older antagonists in constipation, headache, and diarrhea, but palonosetron was significantly safer than older antagonists in dizziness. In keeping with these results, a randomized, double-blind pilot study explored the efficacy and safety of palonosetron for the prevention of CINV in patients with multiple myeloma who received high-dose melphalan for 2 days prior to hematopoietic stem cell transplantation. ${ }^{26}$ Patients were assigned to one of three cohorts receiving palonosetron for 1,2 , or 3 consecutive days. This pilot study with a limited number of patients showed that the 1-, 2-, or 3-day palonosetron dosing cohorts were not statistically different from each other for the occurrence of no emesis (primary end point) throughout the cumulative 7-day study period. In addition, no patient discontinued treatment due to adverse events that occurred at similar frequencies in patients treated with 1 , 2, or 3 days of palonosetron. Most adverse events were of mild-to-moderate intensity and, in the investigator's opinion, unrelated to study medication. 
Table I Meta-analysis of safety data from randomized trials comparing palonosetron to other 5 - $\mathrm{HT}_{3}$ receptor antagonists in the prevention of CINV

\begin{tabular}{lllll}
\hline End point $^{\mathrm{a}}$ (palo vs other) & Palonosetron, $\mathbf{N}^{\mathrm{b}}$ & ${\text { Other antagonists, } \mathbf{N}^{\mathrm{b}}}^{\mathrm{b}}$ & Odds ratio $\left.^{\mathbf{c}} \mathbf{( 9 5 \%} \mathbf{C l}\right)$ & $\boldsymbol{P}_{\text {-value }}$ \\
\hline No constipation & 2,253 & 2,559 & $0.80(0.63-1.01)$ & 0.06 \\
No headache & 2,253 & 2,559 & $1.10(0.84-1.44)$ & 0.40 \\
No diarrhea & 932 & 512 & $1.82(0.74-4.53)$ & 0.19 \\
No dizziness & 985 & 614 & $2.15(1.05-4.4 I)$ & 0.04 \\
\hline
\end{tabular}

Notes: 'Data from Popovic et al;' ba number of patients who were analyzed for each end point; 'for all odds ratios, a value greater than I statistically favors palonosetron. Abbreviations: $\mathrm{CINV}$, chemotherapy-induced nausea and vomiting; $\mathrm{Cl}$, confidence interval; 5- $\mathrm{HT}_{3}$, 5-hydroxytryptamine-3.

The approved dose of palonosetron in Japan is threefold higher than the recommended dose in Western countries and was selected based on two dose-finding trials conducted in Japanese patients. ${ }^{27,28}$ A recent prospective study evaluated the safety and efficacy of repeat doses of palonosetron ( $0.75 \mathrm{mg}$ on days 1 and 3 ) in Japanese patients who received HEC or MEC..$^{29}$ In this study, the safety observation period was from 24 hours before administration of palonosetron until 8 days after administration. The main treatment-related adverse events occurring in 26 patients were constipation (77\%), diarrhea (15\%), pain (8\%), and fever (8\%). No patient experienced severe adverse events.

\section{Cardiac safety}

Heart disease can be a common comorbidity, especially in the growing population of older cancer patients, or a consequence of the malignancy. In addition, electrocardiogram (ECG) changes can be an adverse event resulting from chemotherapy treatment because several antineoplastic agents (especially anthracyclines) can induce ECG alterations, including prolongation of the QT interval. The findings from previous studies of first-generation $5-\mathrm{HT}_{3}$ receptor antagonists suggest that patients who are administered these agents might be at risk of experiencing adverse cardiac events such as ventricular arrhythmia. ${ }^{30}$ One reason for adverse cardiac events seems to be a tendency to block cardiac ion channels, resulting in QT prolongation, when the drug blocks potassium ion channels, and PR prolongation, when the drug blocks sodium ion channels..$^{31}$ It has been demonstrated that human cardiac sodium ion channels are blocked by ondansetron, granisetron, and dolasetron in a concentration-dependent manner. ${ }^{31}$ There have been recent safety concerns related to QT prolongation by first-generation $5-\mathrm{HT}_{3}$ receptor antagonists, leading to multiple label changes and a product recall. ${ }^{32,33}$

Since palonosetron possesses different structure and affinity to $5-\mathrm{HT}_{3}$ receptors and cardiac ion channels, the drug might have unique effects on cardiac repolarization. It should be noted that the frequency of cardiac ion channel blockage is related to the accumulation of drug-bound inactivated channels, which is related to drug in the circulation. ${ }^{34}$ It is likely that palonosetron is effective against emesis within serum concentration levels not high enough for cardiac ion channel blockage. Accordingly, palonosetron might cause less adverse cardiac events within therapeutic concentration, when compared with older antagonists. The recent metaanalysis also investigated the mean change in the corrected QT (QTc) interval, although it was reported only in three trials. ${ }^{1}$ The specific data evaluated in the reviewed studies showed that patients receiving palonosetron experienced a mean increase in the QTc interval after treatment which was significantly lower than that with older antagonists (respective weighted means, 2.45 vs $5.13 \mathrm{~ms} ; P=0.002$ ).

A prospective study assessed the ECG changes caused by palonosetron in 50 cancer patients undergoing chemotherapy. ${ }^{35}$ None of the patients had received anthracycline-containing chemotherapy. ECG recordings were obtained prior to the administration of palonosetron $0.25 \mathrm{mg}$, while subsequent recordings were performed after 30,60, and 90 minutes following the infusion. The study showed no changes in ECG parameters after palonosetron infusion except for a decrease in the heart rate and PR prolongation. No arrhythmogenic effect of palonosetron was observed in this study. Another prospective study determined the acute effects of palonosetron on ECG parameters in 76 cancer patients with normal cardiac function who received the drug for the prevention of CINV. ${ }^{34}$ ECG recordings were obtained before and 30 minutes after palonosetron administration. The patients were administered chemotherapy only after the second ECG recording. Although the median value of the minimal QT interval was higher after palonosetron administration than that prior to palonosetron administration, the difference was not statistically significant ( 330 vs $340 \mathrm{~ms}$, respectively; $P=0.60$ ). Therefore, palonosetron seems to have no acute arrhythmogenic effect related to cardiac repolarization. And last but not the least, clinicians should keep in mind that current labeling of palonosetron includes no warning regarding QT prolongation because a thorough QT study showed virtually no effect of the drug on the QT interval at intravenous doses as high as $2.25 \mathrm{mg} .{ }^{36}$ 


\section{Efficacy of palonosetron Evidence from the meta-analysis}

The recent meta-analysis included 16 RCTs comparing palonosetron to other $5-\mathrm{HT}_{3}$ receptor antagonists in the prevention of CINV. ${ }^{1}$ This study is by far the largest update of previous meta-analyses. RCTs were included if they aimed at comparing palonosetron to older antagonists for the prevention of CINV in at least one of the following five end points: CR (defined as no emetic episode and no rescue antiemetics), complete control (CC; defined as no emetic episode, no rescue antiemetics, and no more than mild nausea), no nausea, no emesis, and no rescue antiemetics. The RCTs that were eligible for the analysis included 2,896 patients randomized to receive palonosetron, and 3,187 patients randomized to any other $5-\mathrm{HT}_{3}$ receptor antagonist. All analyzed trials enrolled adults, with the only exception of a trial that enrolled children. Patients undergoing single-day MEC were enrolled in three trials, whereas eight trials included only patients scheduled to undergo single-day HEC. Corticosteroids were administered to all, some, or no patients in five, two, and three trials, respectively. Only one pilot trial administered the NK-1 receptor antagonist aprepitant to all patients enrolled in the study $(n=40) .{ }^{37}$ Odds ratios (ORs) demonstrated statistical superiority of palonosetron in four of five end points during the acute phase: $\mathrm{CR}(\mathrm{OR}=1.32,95 \%$ confidence interval $[\mathrm{CI}], 1.15-1.52 ; P=0.0001), \mathrm{CC}(\mathrm{OR}=1.33$, 95\% CI, 1.12-1.58; $P=0.001)$, no emesis $(\mathrm{OR}=1.28,95 \%$ CI, $1.10-1.50 ; P=0.002)$, and no nausea $(\mathrm{OR}=1.21,95 \% \mathrm{CI}$, $1.01-1.45 ; P=0.04)$. Palonosetron was also statistically superior to other $5-\mathrm{HT}_{3}$ receptor antagonists in the same end points during the delayed phase: $\mathrm{CR}(\mathrm{OR}=1.63,95 \% \mathrm{CI}, 1.42-1.87$; $P<0.0001)$, CC (OR $=1.60,95 \%$ CI, 1.39-1.84; $P<0.0001)$, no emesis $(\mathrm{OR}=1.57,95 \% \mathrm{CI}, 1.36-1.82 ; P<0.0001)$, and no nausea $(\mathrm{OR}=1.39,95 \% \mathrm{CI}, 1.14-1.69 ; P=0.0009)$. Statistical significance favoring palonosetron was reached for all five end points during the overall phase: $\mathrm{CR}(\mathrm{OR}=1.54,95 \% \mathrm{CI}$, $1.34-1.77 ; P<0.0001)$, CC (OR $=1.54,95 \% \mathrm{CI}, 1.31-1.81$; $P<0.0001)$, no emesis $(\mathrm{OR}=1.54,95 \% \mathrm{CI}, 1.32-1.80$; $P<0.0001$ ), no nausea ( $\mathrm{OR}=1.51,95 \% \mathrm{CI}, 1.20-1.88$; $P=0.0003)$, and no rescue antiemetics $(\mathrm{OR}=1.53,95 \% \mathrm{CI}$, $1.11-2.13 ; P=0.01)$. Therefore, when given without an NK-1 receptor antagonist, palonosetron is more effective than other $5-\mathrm{HT}_{3}$ receptor antagonists for the prevention of CINV caused by both MEC and HEC.

\section{Evidence from trials of palonosetron plus an NK-I receptor antagonist in HEC}

A triple combination of a $5-\mathrm{HT}_{3}$ receptor antagonist, dexamethasone, and an NK-1 receptor antagonist is recommended for the prevention of CINV associated with HEC. ${ }^{38-40}$ The results of randomized trials assessing the efficacy of a triple combination with palonosetron in the setting of HEC are summarized in Table 2.

In a meeting abstract, Hashimoto et $\mathrm{al}^{2}$ reported the findings from a double-blind, randomized, Phase III trial comparing palonosetron to granisetron, both combined with dexamethasone and aprepitant, in patients undergoing cisplatin-based chemotherapy ( single dose of $\geq 50 \mathrm{mg} / \mathrm{m}^{2}$ ). The primary efficacy end point was the rate of CR in the overall study period. Secondary end points included CR in the acute and delayed phases, and total control (TC; defined as no emetic episodes, no rescue antiemetics, and no nausea) during all the study periods. The study had a $90 \%$ power to detect a $10 \%$ improvement in the overall $\mathrm{CR}$ rate. The results indicated antiemetic efficacy in the palonosetron arm only numerically superior to that in the granisetron arm (overall CR: $66 \%$ vs $59 \% ; P=0.05)$. There was no between-arm difference in the rate of acute $\mathrm{CR}$, but significantly more patients receiving palonosetron achieved both $\mathrm{CR}$ and $\mathrm{TC}$ during the delayed phase compared to those in the granisetron arm (CR: $67 \%$ vs $59 \% ; P=0.01$; TC: $49 \%$ vs $41 \% ; P=0.03$ ). The TC rate was also significantly improved in the palonosetron arm during the overall study period ( $48 \%$ vs $41 \% ; P=0.03$ ). In spite of the study not meeting its primary end point, the overall findings indicate that patients receiving palonosetron, dexamethasone, and 3-day aprepitant experience significantly less delayed symptoms associated with cisplatin.

Effective control of nausea still remains an unmet need in research on CINV, but recent evidence suggests that concomitant use of palonosetron and olanzapine, a multiacting receptor antipsychotic, may have the potential to improve the control of delayed nausea. ${ }^{41}$ An open-label, randomized, Phase III trial compared olanzapine to aprepitant, both combined with palonosetron and dexamethasone, for the prevention of CINV caused by cisplatin (single dose of $\geq 70 \mathrm{mg} / \mathrm{m}^{2}$ ) or the combination of an anthracycline and cyclophosphamide (AC). ${ }^{3}$ The primary efficacy end point was the rate of CR in the overall study period. Patients were stratified according to sex and chemotherapy regimen. The study had an $80 \%$ power to detect a $15 \%$ difference between the two antiemetic regimens. Although the overall CR rates were not significantly different between the two arms ( $77 \%$ vs $73 \%$ in the olanzapine and aprepitant arms, respectively), significantly more patients experienced no nausea in the olanzapine arm compared with those in the aprepitant arm during the delayed and overall periods (69\% vs 38\% in each study period; $P<0.01$ ). Therefore, a simplified regimen of 
Table 2 Results of randomized Phase III trials investigating the combination of palonosetron, dexamethasone, and a NK-I receptor antagonist for the prevention of CINV caused by HEC

\begin{tabular}{|c|c|c|c|c|c|c|}
\hline \multirow[t]{2}{*}{ Study (chemotherapy) } & \multirow{2}{*}{$\begin{array}{l}\text { Antiemetic regimen } \\
\text { (dose in } \mathrm{mg} \text { ) }\end{array}$} & \multirow[t]{2}{*}{$\mathbf{N}$} & \multirow[t]{2}{*}{ Study period } & \multicolumn{2}{|l|}{ CR (\%) } & \multirow[t]{2}{*}{$P$-value } \\
\hline & & & & Experimental & Control & \\
\hline \multirow[t]{6}{*}{ Hashimoto et al ${ }^{2}$ (cisplatin-based) } & Day I: Palo (0.75) + Dex (9.9) + Apr & 414 & Day I & 92 & 92 & 1.0 \\
\hline & Days 2 and $3:$ Apr & & & & & \\
\hline & Days 2-4: Dex (6.6) & & Days 2-5 & 67 & 59 & 0.01 \\
\hline & Day I: Gra (I) + Dex (9.9) & 413 & & & & \\
\hline & Days 2 and $3:$ Apr & & Days $1-5^{a}$ & 66 & 59 & 0.05 \\
\hline & Days 2-4: Dex (6.6) & & & & & \\
\hline \multirow[t]{5}{*}{ Navari et al ${ }^{3}$ (cisplatin- or AC-based) } & Day I: Palo $(0.25)+\operatorname{Dex}(20)+$ Ola $(10)$ & 121 & Day I & 97 & 87 & $>0.05$ \\
\hline & Days $2-4$ Ola & & Days 2-5 & 77 & 73 & $>0.05$ \\
\hline & Day I: Palo (0.25) + Dex (I2) + Apr & 120 & Days $1-5^{a}$ & 77 & 73 & $>0.05$ \\
\hline & Days 2 and $3: \mathrm{Apr}$ & & & & & \\
\hline & Days 2-4: Dex (8) & & & & & \\
\hline \multirow[t]{4}{*}{ Hesketh et al ${ }^{4}$ (cisplatin-based) } & Day I: NEPA + Dex (I2) & 135 & Day I & 99 & 90 & $<0.01$ \\
\hline & Days 2-4: Dex (8) & & & & & \\
\hline & Day I: Palo (0.50) + Dex (20) & 136 & Days 2-5 & 90 & 80 & 0.05 \\
\hline & Days 2-4: Dex (16) & & Days $1-5^{a}$ & 88 & 76.5 & 0.01 \\
\hline \multirow[t]{5}{*}{ Roila et al ${ }^{5}$ (cisplatin-based) } & Day I: Palo (0.25) + Dex (I2) + Apr & 137 & Day I & 95 & 95 & 1.0 \\
\hline & Days 2-4: Dex $(16)+\operatorname{Mtc}(20 \times 4)$ & & Days $2-5^{a}$ & 83 & 80 & 0.38 \\
\hline & Day I: Palo $(0.25)+\operatorname{Dex}($ I 2$)+A p r$ & 147 & Days I-5 & NR & NR & \\
\hline & Days 2 and 3: Apr & & & & & \\
\hline & Days 2-4: Dex (8) & & & & & \\
\hline
\end{tabular}

Note: aPrimary efficacy end point.

Abbreviations: CINV, chemotherapy-induced nausea and vomiting; $\mathrm{HEC}$, highly emetogenic chemotherapy; $\mathrm{CR}$, complete response (no vomiting, and no rescue antiemetics); AC, anthracycline and cyclophosphamide; NR, not reported; Apr, aprepitant; Dex, dexamethasone; Ola, olanzapine; Mtc, metoclopramide; NEPA, combination of netupitant $300 \mathrm{mg}$ and palonosetron $0.50 \mathrm{mg}$; Palo, palonosetron; NK-I, neurokinin-I; Gra, granisetron.

palonosetron, single-dose dexamethasone, and olanzapine might result in more effective control of delayed symptoms, particularly delayed nausea, caused by cisplatin- or AC-based chemotherapy.

NEPA is an oral fixed-dose combination of the novel NK-1 receptor antagonist netupitant and palonosetron $(0.50 \mathrm{mg})$. The half-life of netupitant is approximately 80 hours, compared with 9-13 hours for aprepitant. ${ }^{42,43}$ A randomized, double-blind, dose-ranging pivotal trial in 694 chemo-naïve patients undergoing single-day cisplatinbased chemotherapy compared three different oral doses of netupitant $(100,200$, and $300 \mathrm{mg}$ ) plus palonosetron to oral palonosetron $(0.50 \mathrm{mg})$, all given on day $1 .{ }^{4}$ Patients in all groups also received oral dexamethasone on days $1-4$. The primary efficacy end point was the rate of CR during the overall study period. The study found that all NEPA doses were significantly more effective than palonosetron alone, but the highest NEPA dose was incrementally more effective than the other NEPA doses for all endpoints. Another double-blind, randomized, Phase III trial evaluated the superiority of the combination of aprepitant and dexamethasone compared to metoclopramide plus dexamethasone in the prevention of delayed emesis in patients receiving cisplatin
( single dose of $\left.\geq 50 \mathrm{mg} / \mathrm{m}^{2}\right) .{ }^{5}$ All patients received on day 1 the three-drug regimen of palonosetron, dexamethasone, and aprepitant for the prevention of acute CINV. This superiority trial did not meet its primary end point (CR rate in the delayed phase) as well as any other secondary end point of efficacy. It must be pointed out that the study had a low power $(62 \%$ instead of $80 \%)$ due to difficulty in the accrual of patients. It is also interesting to note that among the patients receiving aprepitant for 3 days, the CR rates during the acute and delayed phases were consistent with those observed in the NEPA study. ${ }^{4}$

\section{Evidence from trials of palonosetron plus an NK-I receptor antagonist in AC}

Since breast cancer patients undergoing the combination of $\mathrm{AC}$ have a particularly high risk of developing acute and delayed CINV, the guidelines from the Multinational Association of Supportive Care in Cancer (MASCC) and ESMO separated AC from other MEC, while the guidelines from other major organizations reclassified this combination as highly emetogenic. ${ }^{38-40}$ All guidelines recommend the use of an NK-1 receptor antagonist for the prevention of CINV in this special setting. ${ }^{38-40}$ The results of randomized trials assessing 
the efficacy of a triple combination with palonosetron in the setting of AC are summarized in Table 3.

A large, double-blind, randomized, Phase III trial compared NEPA with palonosetron in patients receiving ACbased chemotherapy. ${ }^{6}$ The vast majority of patients (98\%) were women with breast cancer. Patients were randomly assigned to receive a single oral dose of NEPA or a single oral dose of palonosetron, each with oral dexamethasone administered on day 1 only. The primary efficacy end point was the rate of $\mathrm{CR}$ in the delayed study period. After the first cycle, NEPA was significantly more effective than palonosetron alone as assessed by CR rate in the acute, delayed, and overall phases. Similarly, NEPA was consistently more effective than palonosetron during the delayed and overall phases for secondary efficacy end points of no emesis (delayed phase: $82 \%$ vs $76 \% ; P=0.004$; overall phase: $80 \%$ vs $72 \% ; P<0.001$ ), and no significant nausea (delayed phase: $77 \%$ vs $71 \% ; P=0.014$; overall phase: $75 \%$ vs $69 \%$; $P=0.020)$. Overall, the study findings suggest that the use of corticosteroids beyond day 1 might not be necessary with NEPA in breast cancer patients undergoing AC. Another double-blind, randomized, Phase III trial evaluated the comparative efficacy of either dexamethasone or aprepitant for the prevention of delayed CINV in women with breast cancer who were receiving AC. ${ }^{7}$ The primary efficacy end point was the rate of $\mathrm{CR}$ in the delayed phase. The study had a projected power of $90 \%$ to detect a $12 \%$ increase of $\mathrm{CR}$ rate in the delayed period induced by dexamethasone compared with aprepitant. All patients received the same triple combination of palonosetron, dexamethasone, and aprepitant administered on day 1 for prophylaxis of acute CINV. This superiority trial did not meet its primary end point as well as any other secondary end point of efficacy. Although there was a reduction of power due to difficulty in the accrual of patient, significantly more patients receiving additional dexamethasone doses experienced insomnia or heartburn in the delayed period following the first cycle of AC. In spite of the intrinsic limitations of cross-study comparison, it is interesting to note that the rate of delayed CR (79\%) observed in the 3-day aprepitant arm well compares with that (55\%) in a large, double-blind, randomized Phase III trial in breast cancer patients $(n=857)$ who were receiving a triple combination with ondansetron ( $8 \mathrm{mg}$ twice a day on day 1 only) for the prevention of CINV caused by AC. ${ }^{44}$

More recently, a double-blind, randomized, Phase III trial evaluated the superiority of palonosetron compared to granisetron, both combined with the NK-1 receptor antagonist fosaprepitant and 3-day dexamethasone, for the prevention of CINV in breast cancer patients undergoing $\mathrm{AC}{ }^{8}$ In this trial, the primary efficacy end point was the rate of CR in the delayed phase. The trial found that the proportion of patients achieving delayed $\mathrm{CR}$ in the palonosetron arm was comparable to that observed in the granisetron arm. In spite of this, significantly more patients receiving palonosetron were free from delayed nausea ( $72 \%$ vs $60 \%$; absolute risk difference of $12 \%, P=0.03$ ). There was also a trend toward a greater efficacy

Table 3 Results of randomized Phase III trials investigating the combination of palonosetron, dexamethasone, and an NK-I receptor antagonist for the prevention of CINV caused by AC

\begin{tabular}{|c|c|c|c|c|c|c|}
\hline \multirow[t]{2}{*}{ Study } & \multirow[t]{2}{*}{ Antiemetic regimen (dose in $\mathrm{mg}$ ) } & \multirow[t]{2}{*}{$\mathbf{N}$} & \multirow{2}{*}{$\begin{array}{l}\text { Study } \\
\text { period }\end{array}$} & \multicolumn{2}{|l|}{ CR (\%) } & \multirow[t]{2}{*}{ P-value } \\
\hline & & & & Experimental & Control & \\
\hline \multirow[t]{4}{*}{ Aapro et $\mathrm{al}^{6}$} & Day I: NEPA + Dex (I2) & 724 & Day I & 88 & 85 & 0.04 \\
\hline & Days 2 and 3: no treatment & & Days $2-5^{a}$ & 77 & 69.5 & 0.001 \\
\hline & Day I: Palo (0.50) + Dex (20) & 725 & Days I-5 & 74 & 67 & 0.001 \\
\hline & Days 2 and 3: no treatment & & & & & \\
\hline \multirow[t]{4}{*}{ Roila et $\mathrm{al}^{7}$} & Day I: Palo (0.25) + Dex (8) + Apr & 273 & Day I & 88 & 85 & 0.39 \\
\hline & Days 2 and 3: Dex (8) & & Days $2-5^{a}$ & 79.5 & 79.5 & 1.0 \\
\hline & Day I: Palo $(0.25)+\operatorname{Dex}(8)+A p r$ & 278 & Days I-5 & NR & NR & \\
\hline & Days 2 and 3: Apr & & & & & \\
\hline \multirow[t]{6}{*}{ Matsumoto et $\mathrm{al}^{8}$} & Day I: Palo $(0.75)+\operatorname{Dex}(12)+$ Fosa $(150)$ & 162 & Day I & 76 & 73 & 0.66 \\
\hline & Day 2: Dex (4) & & Days $2-5^{a}$ & 62 & 60 & 0.80 \\
\hline & Day 3: Dex (8) & & & & & \\
\hline & Day I: Gra (I) + Dex (I2) + Fosa (I50) & 164 & Days I-5 & 55 & 55 & 1.0 \\
\hline & Day 2: Dex (4) & & & & & \\
\hline & Day 3: Dex (8) & & & & & \\
\hline
\end{tabular}

Note: aPrimary efficacy end point.

Abbreviations: CINV, chemotherapy-induced nausea and vomiting; AC, anthracycline and cyclophosphamide; CR, complete response (no vomiting, and no rescue antiemetics); NR, not reported; Apr, aprepitant; Dex, dexamethasone; Fosa, fosaprepitant; Gra, granisetron; NEPA, combination of netupitant 300 mg and palonosetron 0.50 $\mathrm{mg}$; Palo, palonosetron; NK-I, neurokinin-I. 
of palonosetron in the control of delayed vomiting $(90 \%$ vs $82 \%$; absolute risk difference of $8 \%, P=0.08$ ). Overall, these findings indicate that palonosetron provides additional protection against delayed symptoms in patients undergoing $\mathrm{AC}$ who also receive an NK-1 receptor antagonist.

\section{Evidence from trials of a dexamethasone- sparing approach with palonosetron}

Three recently reported randomized trials tested the hypothesis that additional dexamethasone doses beyond day 1 of MEC administration may not be necessary when patients receive palonosetron for the control of acute CINV (Table 4). In an open-label, randomized, noninferiority trial, palonosetron plus single-dose dexamethasone administered before a broad range of MEC regimens (oxaliplatin based 36\%, AC based 35\%, carboplatin based $11 \%$, irinotecan based $9 \%$, and other MEC 9\%) provided protection against CINV, which was noninferior to that of palonosetron plus 3-day dexamethasone during the overall study period. ${ }^{10}$ This finding is consistent with the results of a double-blind, randomized, Phase III trial with a similar design that demonstrated the noninferiority of palonosetron plus 1-day dexamethasone in a homogeneous population of chemotherapy-naïve women undergoing AC for breast cancer. ${ }^{9}$ A recent meta-analysis of individual patient data confirmed the noninferiority of the dexamethasone-sparing regimen in breast cancer patients treated with $\mathrm{AC}$, even after adjusting for the influence of age. ${ }^{45}$ More recently, an open-label, randomized, noninferiority trial confirmed that the dexamethasonesparing regimen administered before a broad range of non-AC MEC regimens (oxaliplatin based 73\%, irinotecan based
$13 \%$, carboplatin based $12 \%$, and other MEC $2 \%$ ) provided protection against CINV, which was noninferior to that of palonosetron plus 3-day dexamethasone. ${ }^{11}$ Overall, the findings suggest that tailoring dexamethasone dosing to reduce exposure in patients receiving palonosetron on day 1 of MEC or AC is not associated with a clinically significant loss in antiemetic protection during the 5-day observation period.

\section{Evidence on oral palonosetron formulation in the prevention of CINV}

Since both oral and intravenous formulations of older $5-\mathrm{HT}_{3}$ receptor antagonists are effective for the prevention of CINV, an oral palonosetron formulation was developed and compared with the intravenous formulation. Although a similar pharmacokinetic profile was achieved with similar oral and intravenous doses of palonosetron in terms of area-under-theconcentration-time-curve drug exposure, the possibility that the lower peak concentration following oral administration might adversely affect efficacy during the acute period suggested that higher oral doses had to be evaluated. In a doubleblind, double-dummy, dose-ranging trial, 651 patients were randomly assigned to one of four treatments prior to MEC: oral palonosetron $(0.25,0.50$, or $0.75 \mathrm{mg})$ or intravenous palonosetron $(0.25 \mathrm{mg})$. Patients in each treatment group were randomized (1:1 ratio) to receive either a single dose of dexamethasone ( $8 \mathrm{mg}$ ) intravenously or matched placebo on day 1 in addition to palonosetron. ${ }^{46}$ The primary efficacy hypothesis was that at least one dose of oral palonosetron was noninferior to the approved intravenous dose of palonosetron using a maximum delta of $-15 \%$, considering the $\mathrm{CR}$ rate

Table 4 Results of Phase III noninferiority trials investigating a dexamethasone-sparing approach with palonosetron

\begin{tabular}{|c|c|c|c|c|c|c|}
\hline \multirow[t]{2}{*}{ Study (chemotherapy) } & \multirow{2}{*}{$\begin{array}{l}\text { Antiemetic regimen } \\
\text { (dose in } \mathrm{mg} \text { ) }\end{array}$} & \multirow[t]{2}{*}{$\mathbf{N}$} & \multirow{2}{*}{$\begin{array}{l}\text { Study } \\
\text { period }\end{array}$} & \multicolumn{2}{|l|}{ CR (\%) } & \multirow[t]{2}{*}{$\mathbf{R D}^{\mathrm{a}}(95 \% \mathrm{Cl}), \%$} \\
\hline & & & & I-day regimen & 3-day regimen & \\
\hline \multirow[t]{4}{*}{ Aapro et $\mathrm{al}^{9}(\mathrm{AC} M E C)^{\mathrm{b}}$} & Day I: Palo (0.25) + Dex (8) & $15 \mid$ & Day I & 69.5 & 68.5 & $-0.1(-1 \mathrm{I} .7 \text { to } \mid \mathrm{I} .6)^{\mathrm{d}}$ \\
\hline & Days 2 and 3: placebo & & Days 2-5 & 62.3 & 65.8 & \\
\hline & Day I: Palo (0.25) + Dex (8) & 149 & Days $1-5^{c}$ & 53.6 & 53.7 & \\
\hline & Days 2 and 3: $\operatorname{Dex}(8)$ & & & & & \\
\hline \multirow[t]{4}{*}{ Celio et a ${ }^{10}$ (AC or non-AC MEC) } & Day I: Palo (0.25) + Dex (8) & 166 & Day I & 88.6 & 84.3 & $-3.6(-13.5 \text { to } 6.3)^{d}$ \\
\hline & Days 2 and 3: no treatment & & Days $2-5$ & 68.7 & 77.7 & \\
\hline & Day I: Palo (0.25) + Dex (8) & 166 & Days $1-5^{c}$ & 67.5 & 71.1 & \\
\hline & Days 2 and $3: \operatorname{Dex}(8)$ & & & & & \\
\hline \multirow[t]{4}{*}{ Komatsu et al" (non-AC MEC) } & Day I: Palo (0.75) + Dex (9.9) & $|5|$ & Day I & 93.4 & 92.2 & $2.5(-7.8 \text { to } 12.8)^{d}$ \\
\hline & Days 2 and 3: no treatment & & Days $2-5$ & 66.9 & 64.9 & \\
\hline & Day I: Palo (0.75) + Dex (9.9) & 154 & Days $1-5^{c}$ & 66.2 & 63.6 & \\
\hline & Days 2 and 3: $\operatorname{Dex}(8)$ & & & & & \\
\hline
\end{tabular}

Notes: aRisk difference was calculated as I-day regimen response minus 3-day regimen response with $95 \%$ Cl; bthe MASCC/ESMO guidelines classify MEC as AC and nonAC MEC; ' primary efficacy end point; ${ }^{~}$ noninferiority hypothesis was proven as the lower boundary of the $95 \% \mathrm{Cl}$ of risk difference was greater than the preset threshold $(-15 \%)$.

Abbreviations: AC, anthracycline and cyclophosphamide; MEC, moderately emetogenic chemotherapy; CR, complete response (no vomiting, and no rescue anti-emetics); Dex, dexamethasone; Palo, palonosetron; CI, confidence interval; MASCC, Multinational Association of Supportive Care in Cancer; ESMO, European Society for Medical Oncology; RD, risk difference. 
during the acute phase after chemotherapy initiation. Acute CR rates were $74 \%, 76 \%, 74 \%$, and $70 \%$ for all patients receiving the palonosetron $0.25,0.50$, and $0.75 \mathrm{mg}$ oral doses, and for intravenous palonosetron, respectively. The addition of dexamethasone improved acute CR rate by at least $15 \%$ for all groups except oral palonosetron $0.25 \mathrm{mg}$, where the acute CR improvement was approximately $7 \%$. The type and severity of adverse events were similar for all oral and intravenous palonosetron groups, and were typical for the $5-\mathrm{HT}_{3}$ receptor antagonist class (primarily headache and constipation). Among the tested oral treatments, a palonosetron $0.50 \mathrm{mg}$ oral dose was favored for the prevention of CINV caused by MEC due to a numerical gain in efficacy without a side effect disadvantage. Therefore, the FDA and EMA approved oral palonosetron $0.50 \mathrm{mg}$ for the prevention of acute nausea and vomiting associated with MEC regimens.

More recently, a double-blind, randomized, Phase III trial compared the efficacy and safety of oral palonosetron to intravenous palonosetron for the prevention of CINV caused by cisplatin (a single dose of $\geq 70 \mathrm{mg} / \mathrm{m}^{2}$ ). ${ }^{47}$ Patients received oral palonosetron $(0.50 \mathrm{mg} ; \mathrm{n}=369)$ or intravenous palonosetron $(0.25 \mathrm{mg} ; \mathrm{n}=369)$, each with oral dexamethasone (20 mg on day 1 , then $8 \mathrm{mg}$ twice daily on days $2-4$ ). The primary efficacy hypothesis was to demonstrate noninferiority in terms of patients with a CR within the acute phase. The proportion of patients with a CR in the acute phase was $89 \%$ in the oral palonosetron group and $86 \%$ in the intravenous palonosetron group. The noninferiority of oral palonosetron vs intravenous palonosetron was demonstrated since the lower boundary of the two-sided 99\% CI for the difference in proportions was greater than the predefined threshold set at $-15 \%$. The safety profiles were comparable.

\section{Evidence on palonosetron in the prevention of CINV in children}

A double-blind, randomized, pivotal trial evaluated the efficacy and safety of two different doses of palonosetron compared to ondansetron for the prevention of CINV in pediatric patients aged from full-term neonates to less than 17 years who were scheduled to receive MEC or HEC. ${ }^{48}$ Palonosetron was administered as either $10 \mu \mathrm{g} / \mathrm{kg}$ (maximum total dose of $0.75 \mathrm{mg}$ ) in the lower dose group or $20 \mu \mathrm{g} / \mathrm{kg}$ (maximum total dose of $1.5 \mathrm{mg}$ ) in the higher dose group. All patients randomized to ondansetron received three doses of $0.15 \mathrm{mg} / \mathrm{kg}$ ( $\mathrm{max}-$ imum total dose of $32 \mathrm{mg}$ ). Study drugs were administered on day 1 for up to four study cycles. The primary efficacy end point was the rate of patients achieving $\mathrm{CR}$ in the acute phase following the first chemotherapy cycle. The efficacy evaluation was based on the comparison between palonosetron and ondansetron according to a noninferiority test (predefined threshold of $-15 \%$ ). The majority of patients in all three treatment groups received MEC (69\%). In the evaluable patient population, acute $\mathrm{CR}$ was observed in $54 \%$ of patients $(n=166)$ treated with palonosetron $10 \mu \mathrm{g} / \mathrm{kg}$, $59 \%$ of patients $(\mathrm{n}=165)$ treated with palonosetron $20 \mu \mathrm{g} / \mathrm{kg}$, and $59 \%$ of patients $(n=162)$ treated with ondansetron. The noninferiority was demonstrated only for the higher dose of palonosetron. In line with results observed at cycle 1 , throughout study cycles $2-4$, palonosetron $20 \mu \mathrm{g} / \mathrm{kg}$ treatment group most often achieved the highest $\mathrm{CR}$ rate. There were no clinically relevant differences between treatments in the safety profile in the study population. Therefore, the FDA and EMA approved intravenous palonosetron $20 \mu \mathrm{g} / \mathrm{kg}$ for the prevention of acute nausea and vomiting associated with HEC and prevention of the symptoms associated with MEC in pediatric patients 1 month of age and older.

\section{Economic evidence}

A retrospective claims analysis was recently conducted using a large US database (primarily commercially insured patients) covering the years 2005-2011.49 The analysis evaluated the clinical and economic impacts of delayed CINV events in patients who initiated antiemetic prophylaxis with palonosetron and maintained therapy with this agent compared with patients who received initial and maintenance therapy with an older antagonist (ie, ondansetron, granisetron, or dolasetron). Chemo-naïve patients with a solid cancer who received initial therapy with an emetogenic single-day chemotherapy regimen and a $5-\mathrm{HT}_{3}$ receptor antagonist were included in the analysis. The clinical outcomes included the rates of delayed CINV for cycles 1-6 in the overall study population and by specific antagonist cohort. Delayed CINV was defined as a primary or secondary diagnosis of nausea, vomiting, or dehydration on days 2-5 after chemotherapy or by the use of rescue antiemetics after the administration of chemotherapy. For chemotherapy cycles 2-6, calculations were based on patients who experienced CINV in the previous cycle, maintained the same $5-\mathrm{HT}_{3}$ receptor antagonist for all cycles, and remained on the same level of emetogenicity (ie, single-day MEC or HEC) throughout the entire analysis period (ie, 6 months after therapy initiation). The charges for delayed CINV were calculated as a mean for each patient, and the charges included physician, outpatient facility, inpatient facility, pharmacy, and other medical costs. A total of 26,974 patients met the inclusion criteria for the study. The overall average age was 56 years, and the majority of 
patients across all cohorts were female. Significantly more patients in the palonosetron cohort $(n=18,597)$ received HEC (46\%) than any other type of chemotherapy, which was in contrast to the other antagonist cohorts, where MEC was the predominant regimen (range, 46\%-50\%). However, only $11 \%$ of the patients in the palonosetron cohort received aprepitant at cycle 1 . Dexamethasone was consistently used in the first cycle for all cohorts (range, 88\%-93\%), with the palonosetron cohort having the highest utilization rate $(93 \%)$. The overall rate for delayed CINV at cycle 1 was $16 \%$, and the lowest rate was for palonosetron at $15 \%(P<0.001)$. In addition, the patients initiating therapy with palonosetron had lower rates of delayed CINV throughout all six cycles of chemotherapy. A logistic regression analysis compared individual first-generation antagonists to palonosetron and showed higher odds of CINV in the second cycle for ondansetron (OR 1.41; 95\% CI, 1.14-1.74; $P<0.002$ ), granisetron (OR 1.70; 95\% CI, 1.39-2.08; $P<0.001$ ), and dolasetron (OR 1.65; 95\% CI, 1.27-2.15; $P<0.002$ ). This trend continued through cycle 6 but not all ORs were significant. With regard to economic outcomes, patients receiving palonosetron had the lowest charges associated with delayed CINV over six cycles of chemotherapy. Over six cycles, ondansetron cost an additional \$126,775 compared with palonosetron, granisetron an additional $\$ 169,838$, and dolasetron an additional $\$ 148,960$. In spite of intrinsic limitations of this retrospective analysis, the results are consistent with findings from other studies evaluating palonosetron for delayed CINV in a realworld setting. ${ }^{50-52}$

More recently, a systematic review of the literature on the health care costs and utilization associated with the use of 5- $\mathrm{HT}_{3}$ receptor antagonists for the management of CINV was conducted between 1997 and 2012. ${ }^{53}$ Thirty-two studies were included in the analysis: seven studies reported costs, 18 reported utilization (ie, rescue medication, outpatient, and inpatient services), and seven studies reported both. A total of nine studies included solely HEC regimens, nine included only MEC regimens, and 13 included some combination of chemotherapy. The costs were reported in US dollars (seven studies), in Euros (five studies), and in Canadian dollars (two studies). The studies varied in designs, patients, $5-\mathrm{HT}_{3}$ receptor antagonist regimens, and the definition of outcomes. Therefore, the heterogeneity of the data prevented the authors from conducting a meta-analysis. The US studies reported higher total acquisition costs for CINV prophylaxis with palonosetron compared with ondansetron. However, palonosetron was also generally associated with lower use of rescue medications and outpatient and inpatient services compared with ondansetron or other antagonists. In Europe and Canada, the total pharmacy costs and use of rescue medications reported were lower for patients receiving prophylaxis with palonosetron.

\section{Place of palonosetron in CINV treatment}

In the high-risk setting of AC, the MASCC/ESMO guidelines recommend palonosetron as preferred when an NK-1 receptor antagonist is not available. ${ }^{38}$ For MEC, current guidelines recommend a combination of palonosetron (on day 1) and dexamethasone (on days 1-3). ${ }^{38-40}$ The findings from the latest meta-analysis consistently showed that palonosetron significantly increases the rate of $\mathrm{CR}, \mathrm{CC}$, no emesis, and no nausea in the acute, delayed, and overall phases after single-day HEC or MEC. ${ }^{1}$ This analysis also demonstrated that the absolute risk benefit of palonosetron for delayed CR, delayed CC, and overall CC is greater than $10 \%$ threshold set by MASCC and ESMO to be sufficient to indicate a change of practice guidelines. ${ }^{38}$ In addition, further six end points (ie, overall CR, no delayed emesis, no overall emesis, no delayed nausea, no overall nausea, and no rescue antiemetics in the overall phase) approached the threshold requirement by having between an $8 \%$ and $10 \%$ absolute risk benefit of palonosetron compared to other $5-\mathrm{HT}_{3}$ receptor antagonists. ${ }^{1}$ Consistent with these findings from trials of palonosetron that did not include an NK-1 receptor antagonist, an RCT showed that the triple combination with aprepitant in patients undergoing cisplatin achieved between a 7\% and $8 \%$ absolute risk benefit of palonosetron compared to granisetron for the end points of CR (delayed phase) and TC (delayed and overall phases). ${ }^{2}$ Likewise, an RCT showed that a triple combination with palonosetron resulted in more effective control of delayed nausea compared to a triple combination with granisetron (absolute risk benefit of 12\%) in breast cancer patients undergoing AC. ${ }^{8}$ It is important to note that women with breast cancer receiving $\mathrm{AC}$ are especially vulnerable to nausea, and delayed nausea remains a significant issue. ${ }^{41}$ To put the recent evidence into perspective, it must be pointed out that there was no difference in the acute $\mathrm{CR}$ rate between the palonosetron and granisetron arms in both trials. Therefore, no differential outcome between arms for the acute phase may have had a carry-over effect on the results in the delayed phase. In addition, these results confirm and extend those from the trial of Saito et $\mathrm{al}^{20}$ who first demonstrated that palonosetron plus multiple-day dexamethasone is superior to granisetron plus multiple-day dexamethasone for the control of delayed CINV associated with cisplatin- or AC-based 
chemotherapy. Although the long half-life of palonosetron allows one-time dosing even when prolonged inhibition of $5-\mathrm{HT}_{3}$ receptors over multiple days is desired (eg, to control delayed CINV), it is unlikely that the long half-life alone can account for the persistent superiority of palonosetron when used in combination with an NK-1 receptor antagonist. ${ }^{21-23}$ In light of this, currently available evidence supports the conclusion that the use of a triple combination with palonosetron has the potential to maximize the control of delayed CINV associated with cisplatin or AC without any increase in the complexity of antiemetic regimen. This is a valuable achievement as evidence from the real world suggests that cumbersome prophylaxis for delayed CINV can negatively impact physician's acceptance of practice guidelines. ${ }^{54}$ Since results for the prevention of CINV in clinical trials are substantially superior to those achieved in clinical practice due to the fact that many patients do not adhere to delayed prophylaxis, the use of palonosetron may reduce concerns due to poor patient's adherence to prescribed medications. ${ }^{55}$ The superior efficacy of palonosetron against delayed nausea and vomiting is also indirectly supported by results from three randomized trials that demonstrated the noninferiority of a simplified regimen with palonosetron and single-dose dexamethasone for the control of CINV associated with MEC or AC. ${ }^{9-11}$ In addition, a recent Phase III trial suggests that the use of corticosteroids beyond day 1 might not be necessary with NEPA, a new fixed-dose combination of netupitant and palonosetron, in breast cancer patients undergoing AC. ${ }^{6}$ It also should be noted that efficacy results from MEC and HEC studies with the $0.50 \mathrm{mg}$ oral palonosetron formulation confirm the contribution of this component to the NEPA combination. ${ }^{46,47}$ Overall, these findings indicate that palonosetron provides a valuable therapeutic option to reduce the total dexamethasone dose administered in patients undergoing multiple cycles of MEC or AC, especially for patients with preexisting conditions that could be exacerbated by corticosteroid use (such as diabetes, osteopenia/ osteoporosis, and cataracts). Clinician should also keep in mind other benefits of palonosetron that include the lack of a warning on prolongation of QT interval and no known clinically significant drug-drug interactions.

Current antiemetic guidelines do not consider cost or cost-effectiveness data despite the fact that such guidelines may have significant implications for health care budgets. ${ }^{38-40}$ Unfortunately, the cost of new preferred therapies compared with previously accepted therapies may represent a barrier to a broad acceptance of clinical guidelines. Although the benefit of palonosetron should be weighed against its higher acquisition costs, the potential cost avoidance from CINV should be also considered when evaluating $5-\mathrm{HT}_{3}$ receptor antagonist therapies for formulary placement. A retrospective claims analysis indicates that palonosetron was more often used in the setting of HEC compared with the first-generation antagonists, but there was a lower rate of delayed CINV among patients receiving palonosetron. ${ }^{49}$ This finding, along with the delayed CINV rates that were shown to cost less when palonosetron was administered, are of potential value to payers during medication evaluation when considering the class of medications, as well as each individual agent used. ${ }^{56}$ It is well known that the occurrence of CINV increases the use of health care resources and the overall cost of managing patients undergoing chemotherapy. ${ }^{55}$ A systematic review of the literature on the prevention and treatment of CINV found that the patients receiving palonosetron have lower rescue medication use and less inpatient and outpatient services despite higher acquisition treatment costs. ${ }^{53}$ Overall, the economic evidence available seems to support the conclusion that the higher costs of palonosetron-based regimens may be partially offset by savings made in other health care resources.

\section{Conclusion}

The evidence currently available indicates that palonosetron, a second-generation 5- $\mathrm{HT}_{3}$ receptor antagonist, significantly adds to the clinician's ability to effectively control CINV, particularly delayed CINV, in patients undergoing MEC or HEC. It also should be noted that improved efficacy of antiemetic coverage may potentially impact on patient satisfaction, which remains a key consideration in the overall management of cancer patients. The high safety profile and the opportunity to reduce the total corticosteroid dose with no loss in efficacy against delayed CINV should also contribute to a wider use of palonosetron in clinical practice.

\section{Disclosure}

The authors report no conflicts of interest in this work.

\section{References}

1. Popovic M, Warr DG, De Angelis C, et al. Efficacy and safety of palonosetron for the prophylaxis of chemotherapy-induced nausea and vomiting (CINV): a systematic review and meta-analysis of randomized controlled trials. Support Care Cancer. 2014;22(6):1685-1697.

2. Hashimoto H, Yamanaka T, Shimada Y, et al. Palonosetron (PALO) versus granisetron (GRA) in the triplet regimen with dexamethasone (DEX) and aprepitant (APR) for preventing chemotherapy-induced nausea and vomiting (CINV) in patients (pts) receiving highly emetogenic chemotherapy (HEC) with cisplatin (CDDP): a randomized, double-blind, phase III trial [abstract]. J Clin Oncol. 2013;31(Suppl):9621. 
3. Navari RM, Gray SE, Kerr AC. Olanzapine versus aprepitant for the prevention of chemotherapy-induced nausea and vomiting: a randomized phase III trial. J Support Oncol. 2011;9(5):188-195.

4. Hesketh PJ, Rossi G, Rizzi G, et al. Efficacy and safety of NEPA, an oral combination of netupitant and palonosetron, for prevention of chemotherapy-induced nausea and vomiting following highly emetogenic chemotherapy: a randomized dose ranging pivotal trial. Ann Oncol. 2014;25(7):1340-1346.

5. Roila F, Ruggeri B, Ballatori E, et al. Aprepitant versus metoclopramide, both combined with dexamethasone, for prevention of cisplatininduced delayed emesis: a randomized, double-blind study. Ann Oncol. 2015;26(6):1248-1253.

6. Aapro M, Rugo H, Rossi G, et al. A randomised phase III study evaluating the efficacy and safety of NEPA, a fixed-dose combination of netupitant and palonosetron, for prevention of chemotherapy-induced nausea and vomiting following moderately emetogenic chemothjerapy. Ann Oncol. 2014;25(7):1328-1333.

7. Roila F, Ruggeri B, Ballatori E, Del Favero A, Tonato M. Aprepitant versus dexamethasone for preventing chemotherapy-induced delayed emesis in patients with breast cancer: a randomized double-blind study. $J$ Clin Oncol. 2014;32(2):101-106.

8. Matsumoto K, Takahashi M, Sato K, et al. Palonosetron or granisetron for prevention of CINV in patients with breast cancer receiving dexamethasone and fosaprepitant following anthacycline plus cyclophosphamide (AC) regimen. J Clin Oncol. 2015;33(Suppl):9598.

9. Aapro M, Fabi A, Nolè F, et al. Double-blind, randomised, controlled study of the efficacy and tolerability of palonosetron plus dexamethasone for 1 day with or without dexamethasone on days 2 and 3 in the prevention of nausea and vomiting induced by moderately emetogenic chemotherapy. Ann Oncol. 2010;21(5):1083-1088.

10. Celio L, Frustaci S, Denaro A, et al. Palonosetron in combination with 1-day versus 3-day dexamethasone for prevention of nausea and vomiting following moderataely emetogenic chemotherapy: a randomized, multicenter, phase III trial. Support Care Cancer. 2011;19(8):1217-1225.

11. Komatsu Y, Okita K, Yuki S, et al. Open-label, randomized, comparative, phase III study on effects of reducing steroid use in combination with palonosetron. Cancer Sci. 2015;106(7):891-895.

12. Hesketh PJ. Chemotherapy-induced nausea and vomiting. $N$ Engl J Med. 2008;358(23):2482-2494.

13. Roila F, Donati D, Tamberi S, Margutti G. Delayed emesis: incidence, pattern, prognostic factors and optimal treatment. Support Care Cancer. 2002;10(2):88-95.

14. Grunberg SM, Deuson RR, Mavros P, et al. Incidence of chemotherapyinduced nausea and emesis aster modern antiemetics. Cancer. 2004; 100(10):2261-2268.

15. Italian Group for Antiemetic Research. Cisplatin-induced delayed emesis: pattern and prognostic factors during three subsequent cycles. Ann Oncol. 1994;5(7):585-589.

16. Italian Group for Antiemetic Research. Dexamethasone alone or in combination with ondansetron for the prevention of delayed nausea and vomiting induced by chemotherapy. $N$ Engl J Med. 2000; 342(21):1554-1559.

17. Geling O, Eichler H-G. Should 5-hydroxytryptamine-3 receptor antagonists be administered beyond 24 hours after chemotherapy to prevent delayed emesis? Systematic re-evaluation of clinical evidence and drug cost implications. J Clin Oncol. 2005;23(6):1289-1294.

18. Hesketh PJ. Comparative review of 5-HT3 receptor antagonists in the treatment of acute chemotherapy-induced nausea and vomiting. Cancer Invest. 2000;18(2):163-173.

19. Aapro MS, Grunberg SM, Manikhas GM, et al. A phase III, doubleblind, randomized trial of palonosetron compared with ondansetron in preventing chemotherapy-induced nausea and vomiting following highly emetogenic chemotherapy. Ann Oncol. 2006;17(9):1441-1449.

20. Saito M, Aogi K, Sekine I, et al. Palonosetron plus dexamethasone versus granisetron plus dexamethasone for prevention of nausea and vomiting during chemotherapy: a double-blind, double-dummy, randomized, comparative phase III trial. Lancet Oncol. 2009;10(2):115-124.
21. Rojas C, Stathis M, Thomas AG, et al. Palonosetron exhibits unique molecular interactions with the 5-HT3 receptor. Anesth Analg. 2008; 107(2):469-478.

22. Rojas C, Thomas AG, Alt J, et al. Palonosetron triggers 5-HT(3) receptor internalization and causes prolonged inhibition of receptor function. Eur J Pharmacol. 2010;626(2-3):193-199.

23. Rojas C, Li Y, Zhang J, et al. The antiemetic 5-HT3 receptor antagonist palonosetron inhibits substance $\mathrm{P}$-mediated responses in vitro and in vivo. J Pharmacol Exp Ther. 2010;335(2):362-368.

24. Stolz R, Cyong JC, Shah A, Parisi S. Pharmacokinetic and safety evaluation of palonosetron, a 5-hydroxytryptamine-3 receptor antagonist, in US and Japanese healthy subjects. J Clin Pharmacol. 2004;44(5):520-531.

25. Eisenberg P, Mackintosh FR, Ritch P, Cornett PA, Macciocchi A. Efficacy, safety and pharmacokinetics of palonosetron in patients receiving highly emetogenic cisplatin-based chemotherapy: a dose-ranging clinical study. Ann Oncol. 2004;15(2):330-337.

26. Giralt SA, Mangan KF, Maziarz RT, et al. Three palonosetron regimens to prevent CINV in myeloma patients receiving multiple-day high-dose melphalan and hematopoietic stem cell transplantation. Ann Oncol. 2011;22(4):939-946.

27. Maemondo M, Masuda N, Sekine I, et al. PALO Japanese Cooperative Study Group. A phase II study of palonosetron combined with dexamethasone to prevent nausea and vomiting induced by highly emetogenic chemotherapy. Ann Oncol. 2009;20(11):1860-1866.

28. Segawa Y, Aogi K, Inoue K, et al. PALO Japanese Cooperative Study Group. A phase II dose-ranging study of palonosetron in Japanese patients receiving moderately emetogenic chemotherapy, including anthracycline and cyclophosphamide-based chemotherapy. Ann Oncol. 2009;20(11):1874-1880.

29. Ikari Y, Ogata K, Nakashima Y, et al. Safety and pharmacokinetic evaluation of repeated intravenous administration of palonosetron $0.75 \mathrm{mg}$ in patients receiving highly or moderately emetogenic chemotherapy. Support Care Cancer. 2014;22(7):1959-1964.

30. Keefe DL. The cardiotoxic potential of the 5-HT(3) receptor antagonist antiemetics: is there cause for concern? Oncologist. 2002;7(1):65-72.

31. Kuryshev YA, Brown AM, Wang L, Benedict CR, Rampe D. Interactions of the 5-hydroxytryptamine 3 antagonist class of antiemetic drugs with human cardiac ion channels. J Pharmacol Exp Ther. 2000;295(2):614-620.

32. FDA. Drug safety communication: abnormal heart rhythms associated with use of Anzemet (dolasetron mesylate) [webpage on the Internet]. Silver Spring, MD: US Food and Drug Administration [cited December 17, 2010]. Available from: http:/www.fda.gov/Drugs/ DrugSafety/ucm237081.htm. Accessed on February 3, 2015.

33. FDA. Drug safety communication: new information regarding QT prolongation with ondansetron (Zofran) [webpage on the Internet]. Silver Spring, MD: US Food and Drug Administration [cited June 29, 2012]. Available from: http://www.fda.gov/Drugs/DrugSafety/ucm310190. htm. Accessed February 3, 2015.

34. Yavas C, Dogan U, Yavas G, Araz M, Yavas Ata O. Acute effect of palonosetron on electrocardiographic parameters in cancer patients: a prospective study. Support Care Cancer. 2012;20(10):2343-2347.

35. Gonullu G, Demircan S, Demirag MK, Erdem D, Yucel I. Electrocardiographic findings of palonosetron in cancer patients. Support Care Cancer. 2012;20(7):1435-1439.

36. DailyMed. Palonosetron prescribing information [webpage on the Internet]. US National Library of Medicine [cited February 2008]. Available from: http://dailymed.nlm.nih.gov/dailymed/lookup. $\mathrm{cfm}$ ?setid=f4216772-6c37-4ff0-a575-f758390656e3. Accessed February 21, 2015.

37. Wenzell CM, Berger MJ, Blazer MA, et al. Pilot study on the efficacy of an ondansetron- versus palonosetron-containing antiemetic regimen prior to highly emetogenic chemotherapy. Support Care Cancer. 2013; 21(10):2845-2851.

38. Roila F, Herrstedt J, Aapro M, et al. Guideline update for MASCC and ESMO in the prevention of chemotherapy- and radiotherapy-induced nausea and vomiting: results of the Perugia consensus conference. Ann Oncol. 2010;21(Suppl 5):v232-v243. 
39. Basch E, Prestrud AA, Hesketh PJ, et al. Antiemetics: American Society of Clinical Oncology clinical Practice guideline update. J Clin Oncol. 2011;29(31):4189-4198.

40. NCCN Clinical Practice Guidelines in Oncology [homepage on the Internet]. Antiemesis v.2.2014. Available from: http://nccn.org. Accessed January 30, 2015.

41. Navari RM. Management of chemotherapy-induced nausea and vomiting. Drugs. 2013;73(3):249-262.

42. Akynzeo ${ }^{\circledR}$ [prescribing information]. Woodcliff Lake, NJ: Eisai Inc.; 2014.

43. Emend ${ }^{\circledR}$ [prescribing information]. Whitehouse Station, NJ: Merck \& Co Inc., Revised August 2014.

44. Warr DG, Hesketh PJ, Gralla RJ, et al. Efficacy and tolerability of aprepitant for the prevention of chemotherapy-induced nausea and vomiting in patients with breast cancer after moderately emetogenic chemotherapy. J Clin Oncol. 2005;23(12):2822-2830.

45. Celio L, Bonizzoni E, Bajetta E, Sebastiani S, Perrone T, Aapro M. Palonosetron plus single-dose dexamethasone for the prevention of nausea and vomiting in women receiving anthracycline/cyclophosphamide-containing chemotherapy: meta-analysis of individual patient data examining the effect of age on outcome in two phase III trials. Support Care Cancer. 2013;21(2):565-573.

46. Boccia R, Grunberg S, Franco-Gonzales E, Rubenstein E, Voisin D. Efficacy of oral palonosetron compared to intravenous palonosetron for the prevention of chemotherapy-induced nausea and vomiting associated with moderately emetogenic chemotherapy: a phase 3 trial. Support Care Cancer. 2013;21(5):1453-1460.

47. Karthaus M, Tibor C, Lorusso V, et al. Efficacy and safety of oral palonosetron compared with IV palonosetron administered with dexamethasone for the prevention of chemotherapy-induced nausea and vomiting (CINV) in patients with solid tumors receiving highly emetogenic chemotherapy (HEC). Support Care Cancer. 2015. doi $10.1007 / \mathrm{s} 00520-015-2657-1$.
48. Kabickova E, Wachtel A, Basharova E, Spinelli T, Nicolas P, Kovacs G. Palonosetron vs ondansetron: prevention of chemotherapy-induced nausea and vomiting in pediatric patients in a multicycle study. J Clin Oncol. 2015;33(Suppl):10077.

49. Faria C, Li X, Nagl N, McBride A. Outcomes associated with 5-HT - RA therapy selection in patients with chemotherapy-induced nausea and vomiting: a retrospective claims analysis. Am Health Drug Benefits. 2014;7(1):50-58.

50. Tina Shih YC, Xu Y, Elting LS. Costs of uncontrolled chemotherapyinduced nausea and vomiting among working-age cancer patients receiving highly or moderately emetogenic chemotherapy. Cancer. 2007;110(3):678-685.

51. Balu S, Buchner D, Craver C, Gayle J. Palonosetron versus other 5-HT(3) receptor antagonists for prevention of chemotherapy-induced nausea and vomiting in patients with cancer on chemotherapy in a hospital outpatient setting. Clin Ther. 2011;33(4):443-455.

52. Lin SJ, Hatoum HT, Buchner D, Cox D, Balu S. Impact of 5-HT3 receptor antagonists on chemotherapy-induced nausea and vomiting: a retrospective cohort study. BMC Health Serv Res. 2012;12:215.

53. Broder MS, Faria C, Powers A, Sunderji J, Cherepanov D. The impact of 5-HT $\mathrm{HT}_{3} \mathrm{RA}$ use on cost and utilization in patients with chemotherapyinduced nausea and vomiting: systematic review of the literature. Am Health Drug Benefits. 2014;7(3):171-182.

54. Aapro M, Molassiotis A, Dicato M, et al. The effect of guidelineconsistent antiemetic therapy on chemotherapy-induced nausea and vomiting: the Pan European Emesis Registry (PEER). Ann Oncol. 2012; 23(8):1986-1992.

55. Schwartzberg L. Addressing the value of novel therapies in chemotherapy-induced nausea and vomiting. Expert Rev Pharmacoecon Outcomes Res. 2014;14(6):825-834.

56. Wander C. Value of selecting the best antiemetic prophylactic agent for patients using chemotherapy. Am Health Drug Benefits. 2014; 7(1):58.

\section{Core Evidence}

\section{Publish your work in this journal}

Core Evidence is an international, peer-reviewed open-access journal evaluating the evidence underlying the potential place in therapy of drugs throughout their development lifecycle from preclinical to postlaunch. The focus of each review is to evaluate the case for a new drug or class in outcome terms in specific indications and patient groups

\section{Dovepress}

The manuscript management system is completely online and includes a very quick and fair peer-review system, which is all easy to use. Visit http://www.dovepress.com/testimonials.php to read real quotes from published authors. 